\title{
Aberrant DNA methylation of hypothalamic angiotensin receptor in prenatal programmed hypertension
}

\author{
Fumiko Kawakami-Mori, ${ }^{1,2}$ Mitsuhiro Nishimoto, ${ }^{1}$ Latapati Reheman, ${ }^{3}$ Wakako Kawarazaki, ${ }^{1}$ \\ Nobuhiro Ayuzawa,, Kohei Ueda,' Daigoro Hirohama,' Daisuke Kohno, ${ }^{4}$ Shigeyoshi Oba, ${ }^{1}$ \\ Tatsuo Shimosawa, ${ }^{3}$ Takeshi Marumo, ${ }^{1}$ and Toshiro Fujita' \\ 'Division of Clinical Epigenetics, Research Center for Advanced Science and Technology (RCAST), The University of Tokyo, \\ Tokyo, Japan. 'Division of Endocrinology, Mitsui Memorial Hospital, Tokyo, Japan. ${ }^{3}$ Department of Clinical Laboratory, \\ International University of Health and Welfare, School of Medicine, Narita Hospital IUHW, Tokyo, Japan. ${ }^{4}$ Advanced \\ Scientific Research Leaders Development Unit, Gunma University, Gunma, Japan.
}

\begin{abstract}
Maternal malnutrition, which causes prenatal exposure to excessive glucocorticoid, induces adverse metabolic programming, leading to hypertension in offspring. In offspring of pregnant rats receiving a low-protein diet or dexamethasone, a synthetic glucocorticoid, mRNA expression of angiotensin receptor type 1a (Agtr1a) in the paraventricular nucleus (PVN) of the hypothalamus was upregulated, concurrent with reduced expression of DNA methyltransferase 3a (Dnmt3a), reduced binding of DNMT3a to the Agtria gene, and DNA demethylation. Salt loading increased BP in both types of offspring, suggesting that elevated hypothalamic Agtr1a expression is epigenetically modulated by excessive glucocorticoid and leads to adult-onset salt-sensitive hypertension. Consistent with this, dexamethasone treatment of PVN cells upregulated Agtr1a, while downregulating Dnmt3a, and decreased DNMT3a binding and DNA demethylation at the Agtr1a locus. In addition, Dnmt3a knockdown upregulated Agtr1a independently of dexamethasone. Hypothalamic neuron-specific Dnmt3a-deficient mice exhibited upregulation of Agtr1a in the PVN and salt-induced BP elevation without dexamethasone treatment. By contrast, dexamethasonetreated Agtr1a-deficient mice failed to show salt-induced BP elevation, despite reduced expression of Dnmt3a. Thus, epigenetic modulation of hypothalamic angiotensin signaling contributes to salt-sensitive hypertension induced by prenatal glucocorticoid excess in offspring of mothers that are malnourished during pregnancy.
\end{abstract}

Authorship note: FKM and MN contributed equally to this work.

Conflict of interest: The authors have declared that no conflict of interest exists.

License: Copyright 2018, American Society for Clinical Investigation.

Submitted: June 9, 2017

Accepted: September 27, 2018

Published: November 2, 2018

Reference information:

JCI Insight. 2018;3(21):e95625.

https://doi.org/10.1172/jci.

insight. 95625.

\section{Introduction}

The idea that cardiac and metabolic disease can have intrauterine origins, referred to as developmental origins of health and disease (DOHaD), was initially based on early epidemiological studies of prenatal nutrition and late-onset coronary heart disease published by Barker and colleagues in the late 1980s (1). Nowadays, late childbearing, stress, and a low-calorie diet during pregnancy are known to be high risk factors for utero-placental insufficiency (2), which is accompanied by impaired expression of 11- $\beta$-dehydrogenase type 2 (11ß-HSD2), the physiological feto-placental barrier to maternal glucocorticoid, in the placenta (3). Exposure to excessive glucocorticoid during pregnancy reduces birth weight of offspring, leading to permanent hypertension, hyperglycemia, and hypothalamic-pituitary-adrenal axis aberrant activity in adult life. Once developed, prenatally programmed hypertension seems to persist indefinitely and to get progressively worse with age (4). Notably, the young offspring of dams either fed a low-protein diet (LP) or treated with dexamethasone, a synthetic glucocorticoid, during pregnancy do not yet show a significant increase in BP, but - when placed on a high-salt (HS) diet - they exhibit a rise in BP (i.e., salt-sensitive hypertension; refs. $5,6)$. Although the precise mechanism linking neonatal glucocorticoid excess with adult-onset salt-sensitive hypertension is still unknown, there is a plausible hypothesis that the renin-angiotensin system (RAS) in the CNS plays an important role in the development of salt-sensitive hypertension (7-10) and prenatal programed hypertension $(11,12)$ through increased sympathetic nerve activity. Supporting the hypothesis, malnutrition or glucocorticoid exposure induces high BP and a concomitant increase in the response of 
sympathetic activity to physical stress (13), and renal denervation may inhibit prenatal programming of hypertension (14). Moreover, either systemic or icv administration of RAS inhibitors reduces BP in protein-restricted rat offspring $(12,15)$ through the inhibition of sympathetic overactivity. Consistently, the direct injection of antisense oligodeoxynucleotides targeting angiotensin receptor type 1a (Agtr1a, encoding AT1a) into the paraventricular nucleus (PVN) of the hypothalamus prevents increased renin-angiotensin expression in a transgenic animal model, the mRen-2 rat, from developing salt-sensitive hypertension (16), and optogenetic stimulation of PVN Agtrla neurons induces BP elevation (17), implying an important role of hypothalamic Agtrla in the control of sympathetic nerve activity and BP $(18,19)$. Interestingly, the expression of AT1a in the regions of the brain involved in cardiovascular regulation is upregulated not only in dexamethasone-treated rats (20), but also in their offspring exposed to maternal protein restriction (15), suggesting that the increased expression of Agtrla induced by neonatal exposure to excessive glucocorticoids continues into adulthood.

Prenatal exposure to excessive glucocorticoids or stress might induce adverse metabolic programming and lead to hypertension in the offspring. The mechanisms through which prenatal insults or overexposure to glucocorticoids cause permanent hypertension and sympathetic overactivity is currently unknown. However, there has been increasing interest in the role played by epigenetic dynamics - notably, changes in DNA methylation patterns and histone modifications. Epigenetic markers, which regulate chromatin structure and DNA accessibility, are attractive candidates because they can permanently modify gene expression without altering DNA sequence, and once set, they are persistent and irreversible (21). A recent study showed changes in the DNA methylation of hypothalamic obesity-related genes in offspring exposed to a low-fat parental diet (22). Among DNA methyltransferases (DNMTs), including DNMT1, DNMT3a, and DNMT3b, DNMT3a expression is specifically downregulated in the PVN of high-fatfed mice, and PVN-specific deletion of Dnmt3a induces hyperphagia, glucose intolerance, and obesity (23). Given the increased neuronal response to Ang II in the hypothalamus of high-fat-fed mice and the induction of hyperphagia in mice with a PVN-specific deletion of Agtrla, as well as a further increase in their adiposity and body mass when fed a high-fat diet and a significant reduction in their BP (18), the elevated Ang II responsiveness that accompanies obesity could serve as a negative feedback signal for the activation of neurons to alleviate weight gain, with the increased sympathetic activity, in turn, resulting in an increase in BP. Taken together, these findings led us to investigate the possible link between DNMT3a activity and Agtrla mRNA expression in the control of BP, as well as in energy homeostasis. In this study, we tested the hypothesis that prenatal exposure to increased glucocorticoid levels induced by a LP or synthetic glucocorticoid administration might modulate DNA methylation by DNMT3a and that the subsequent permanent changes in the expression of specific genes, key among which is Agtrla, would lead to adverse central nervous programming of angiotensin signaling and postnatal salt-sensitive hypertension.

\section{Results}

Salt-sensitive hypertension in offspring of pregnant mothers exposed to a LP and dexamethasone treatment. A LP during pregnancy in rats (Supplemental Figure 1; supplemental material available online with this article; https:// doi.org/10.1172/JCIInsight95625DS1) was accompanied by reduced placental expression of Hsd11b2 mRNA, encoding 11 $\beta$-HSD2, a key component of the physiological feto-placental barrier to maternal glucocorticoid (Figure 1A). Body weight (BW) at week 1 was lower in the LP-treated offspring than in those born to mothers fed a normal-protein diet (NP); at week 12, however, BW was higher in LP-treated offspring (Figure 1B), with no increase in mRNA expression of leptin in adipose tissue at week 1 or serum leptin concentration at week 12 (Supplemental Figure 2).

Reduced 11 $\beta$-HSD2 activity in the placenta of LP-treated pregnant rodents results in excessive exposure of the fetus to corticosterone (3, 4). Accordingly, we administered $200 \mu \mathrm{g} / \mathrm{kg}$ /day dexamethasone (20) to pregnant rats in the third trimester (F16-21) (Supplemental Figure 1). Consistent with the changes in BW of LP-treated offspring, dexamethasone-treated offspring had lower BW at 1 week and higher BW at 12 weeks than control offspring (Figure 1C).

We next investigated whether either a LP or dexamethasone treatment during the prenatal period can induce hypertension during adult life. At 12 weeks, systolic BP did not differ between LP-treated offspring and NP-treated controls. When we administered a HS diet for 7 days, BP (as measured by telemetry) increased significantly in LP-treated offspring, as previously reported $(5,6)$ — but not in NP-treated offspring (Figure 1D). At the end of salt loading, mean BP was significantly higher in LP-treated offspring 
A

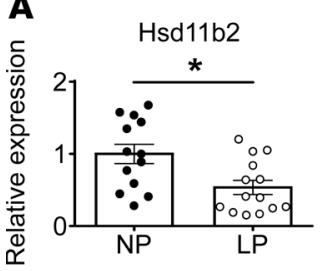

B

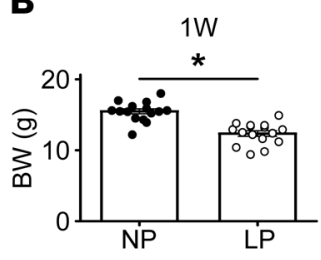

C

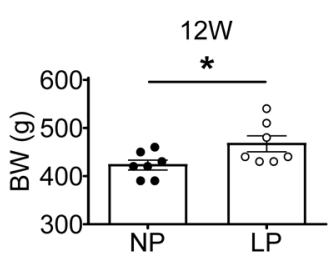

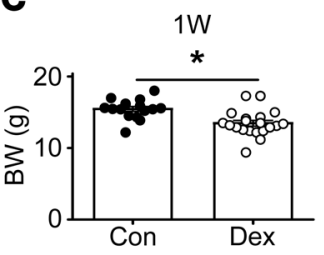
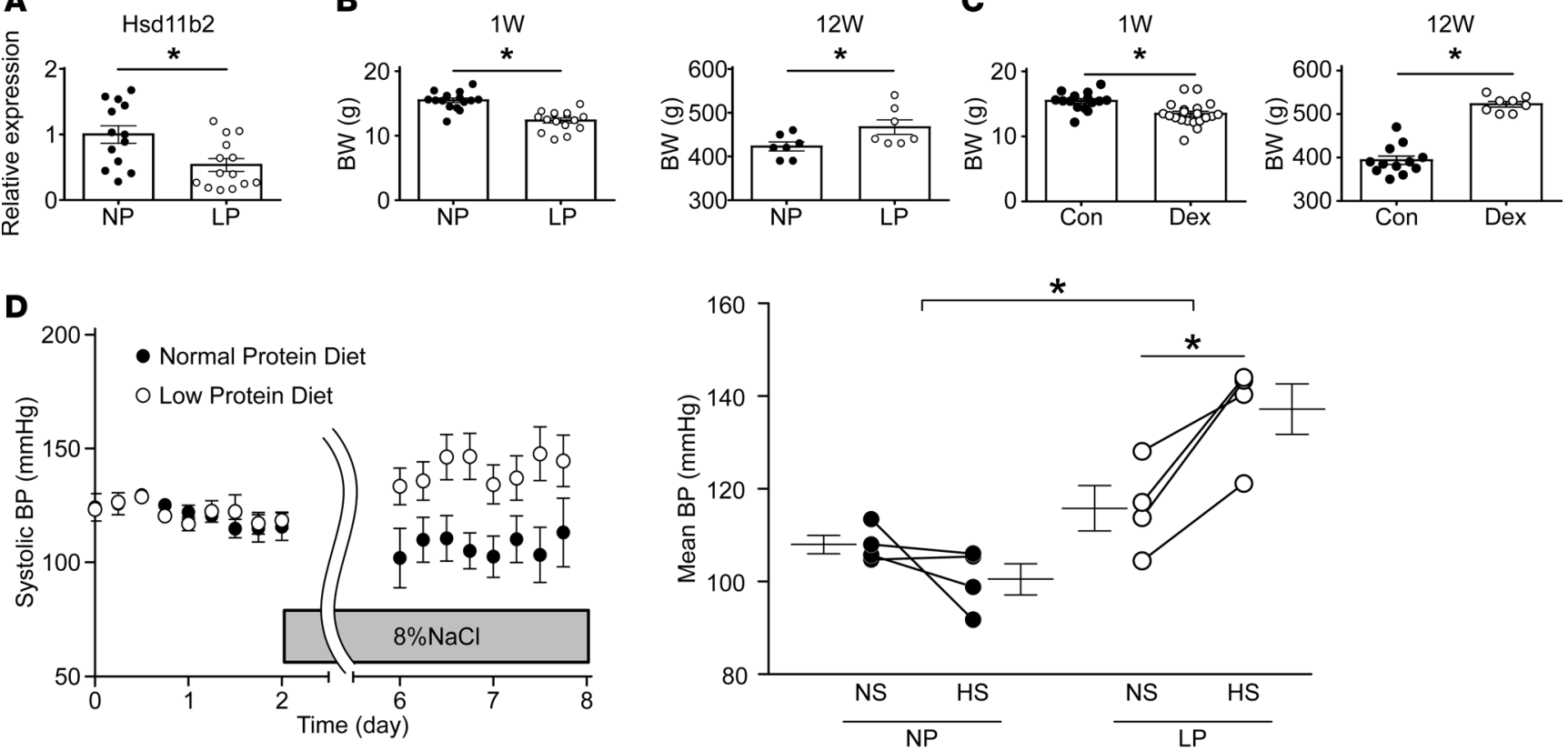

E

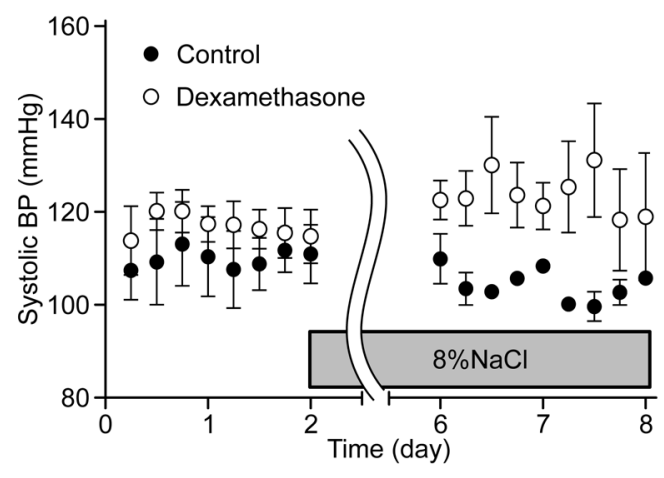

Figure 1. Comparison between offspring treated with a low-protein diet (LP) and those treated with dexamethasone (Dex). (A) Real-time PCR of Hsd11b2 mRNA expression (normalized against Actb) in placenta at the end of the third trimester (F19-20) of pregnant rats receiving a normal-protein diet (NP) $(n=13)$ or a low-protein diet (LP) $(n=14)$. Filled circles, NP-treated rats; open circles, LP-treated rats. (B) Body weight (BW) at weeks $1(n=16)$ and 12 $(n=7)$ in male NP- and LP-treated offspring. (C) BW at weeks 1 and 12 in Dex-untreated (control) $(n=16$ and 12) and Dex-treated ( $n=20$ and 8 , respectively) offspring. Filled circles, control offspring; open circles, Dex-treated offspring. (D) Systolic BP measured by radiotelemetry in NP-treated and LP-treated offspring that received a $0.5 \%$ salt (NS) or $8 \%$ salt (HS) diet for 1 week $(n=4)$ (left panel). Mean arterial pressure by radiotelemetry before and after 1 week of HS in NP-treated and LP-treated offspring (right panel). Filled circles, NP group; open circles, LP group. (E) Systolic BP, measured by radiotelemetry, in control and Dex-treated offspring that received $0.5 \%$ salt (NS) or $8 \%$ salt (HS) diet for 1 week $(n=4)$ (left panel). Mean arterial pressure, measured by radiotelemetry, before and after 1 week of HS in control and Dex-treated offspring (right panel). Filled circles, control offspring; open circles, Dex-treated offspring. Throughout, data represent means \pm SEM. In A, B, and $\mathbf{C},{ }^{*} P<0.05$ versus NP offspring or control offspring ( $t$ test). In $\mathbf{D}$, ${ }^{*} P<0.05$ in NP-treated group versus LP-treated group and in NS versus HS within each group. In E, ${ }^{*} P<0.05$ in control versus Dex-treated offspring and in NS versus HS within each group (2-way repeated ANOVA, Bonferroni post hoc test).

than in NP-treated offspring (Figure 1D). Although BP was comparable between dexamethasone-treated and control rats at week 12, HS increased BP in the dexamethasone-treated offspring but not in the controls, similar to the pattern observed in LP-treated offspring (Figure 1E). In addition, mean BP at the end of salt loading was also higher in dexamethasone-treated rats than in control rats (Figure 1E).

These results led us to hypothesize that exposure to excess glucocorticoid induces prenatal programmed hypertension. To test this hypothesis, we first sought to determine which genes contribute to the hypertension phenotype. Using microarrays, we compared gene expression in the PVN of the hypothalamus between dexamethasone-treated and control groups at week 12. This approach identified 912 genes that were upregulated more than 2-fold in the dexamethasone-treated group relative to the controls; these genes were subjected to pathway analysis (Supplemental Table 1). Agtr1a was included 
in several of the top ranked pathways, including calcium signaling, neuroactive ligand-receptor interaction, and aldosterone synthesis and interaction. Accordingly, we focused on AT1a as a potentially novel regulator of $\mathrm{BP}$ in the hypothalamus.

Epigenomic analysis of salt-sensitive hypertension in offspring of pregnant mothers exposed to a LP. Consistent with the overactivation of central RAS in prenatal programmed hypertension $(12,15,24)$ and the results of the microarray analysis, expression of Agtrla mRNA in the PVN of the hypothalamus was higher in 12-week-old LP offspring than in NP-treated controls. In addition, the LP-treated pups exhibited reduced expression of Dnmt3a, but no changes in Agtr1b, Dnmt1, Dnmt3b, Methyl-CpG binding protein 2 (MeCP2), or Ten-eleven translocation methylcytosine dioxygenase (Tet) 1, 2, 3 (Figure 2A; Supplemental Figure 3). DNA methylation of Agtrla gene in the PVN, measured by methylated DNA immunoprecipitation (MeDIP) analysis (25), was significantly lower in LP-treated offspring than in NP controls (Figure 2B).

To more precisely assess DNA methylation status, we performed bisulfite sequence analysis of the DNA region from +114 to +214 bp of the Agtrla transcription start site (TSS). Demethylation of DNA from $-1,000$ to $+500 \mathrm{bp}$ of a TSS is correlated with active gene expression (26). Figure $2 \mathrm{C}$ shows that $\mathrm{CpG}$ sites were demethylated to a greater extent in LP-treated offspring than in NP-treated offspring.

To determine which DNMTs were responsible for Agtrla demethylation, we performed a ChIP assay. The results revealed that binding of DNMT3a, but not DNMT1, to the Agtr1a locus in the regions $-97 /+107$ bp and $+174 /+366$ bp relative to the TSS (Supplemental Figure 4A and Figure 2D) was reduced in the PVN of LP-treated offspring, suggesting that DNMT3a plays a key role in DNA demethylation and Agtrla transcription. We also found that DNMT3a activity was reduced in the PVN of LP-treated offspring (Supplemental Figure 5). This result implies that expression of Dnmt3a would change methyltransferase activity, proving the role of DNMT3a-altering methylation on Agtrla. Based upon the fact that salt-sensitive hypertension is induced by RAS overactivity (16) and salt-dependent BP elevation in prenatal programmed hypertension can be reversed by the RAS inhibitor (5), we suggest that persistent upregulation of hypothalamic Agtrla mRNA expression, resulting from the DNA demethylation induced by excessive glucocorticoid, causes salt-sensitive hypertension, possibly via sympathetic overactivity $(11,27)$.

Epigenomic analysis of salt-sensitive hypertension in offspring of pregnant mothers treated with dexamethasone. Quantitative PCR (qPCR) analysis revealed that mRNA expression of Agtrla, but not Agtr1b, in the PVN was significantly elevated in the dexamethasone-treated offspring, whereas expression of Dnmt1 and Dnmt3a mRNA was reduced (Figure 3A).

Bisulfite sequencing analysis revealed demethylation of the CpG sites in the region $+114 /+214 \mathrm{bp}$ relative to the TSS of Agtr1a in the PVN of dexamethasone-treated offspring relative to controls, similar to the results obtained in LP-treated offspring (Figure 3B). Moreover, a ChIP assay revealed that binding of DNMT3a, to the Agtrla gene in regions $-97 /+107 \mathrm{bp}$ and $+174 /+366 \mathrm{bp}$ was weaker in the dexamethasone group than in the control group (Figure 3C). However, notwithstanding the demethylation of Agtr1a, binding of DNMT1 was elevated rather than reduced. Because the pattern of DNMT3a binding to the Agtr1a locus was shared between LP-treated and dexamethasone-treated offspring, we concluded that DNMT3a, rather than DNMT1, plays a key role in dexamethasone-induced DNA demethylation of Agtrla during pregnancy.

Changes in DNA methylation with dexamethasone treatment in the PVN cell line. To evaluate the direct effect of dexamethasone on Agtr1a DNA methylation in PVN cells, we applied 10 and $100 \mathrm{nM}$ dexamethasone to the mouse fetal PVN neuronal cell line, N39. Twenty-four-hour treatment with dexamethasone decreased expression of Dnmt1 and Dnmt3a mRNA in a dose-dependent manner (Supplemental Figure 6) and 6-day treatment with $100 \mathrm{nM}$ dexamethasone decreased expression of Dnmt3a, but not Dnmt1, concomitant with upregulation of Agtrla (Figure 4A). Upon demethylation of DNA, presumably, Agtr1a mRNA did not change at the early phase but increased at the late phase (Supplemental Figure 6), as shown in the previous study indicating that the starting time of the increase in mRNA lag a few days behind the start of DNA demethylation (28). Accordingly, DNA methylation in Agtrla decreased significantly in cells subjected to 6-day dexamethasone treatment (Figure 4B), as did binding of DNMT3a, but not DNMT1, to the Agtrla locus (Figure 4C and Supplemental Figure 4B). To further evaluate the involvement of DNMT3a in dexamethasone-induced upregulation of Agtrla, we transfected small interfering RNA against Dnmt3a (siDnmt3a) into a mouse hypothalamic cell line (Supplemental Figure 7) and observed a significant decrease in DNA methylation of Agtrla (Figure 4D). Notably, silencing of the Dnmt3a gene increased Agtr1a mRNA expression to levels similar to those observed after dexamethasone 
A

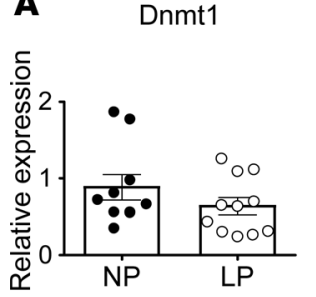

Dnmt3a

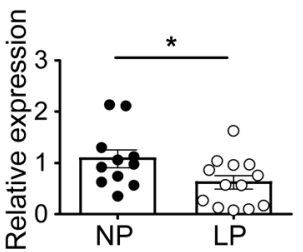

Dnmt3b

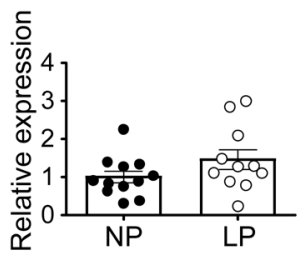

Agtr1a

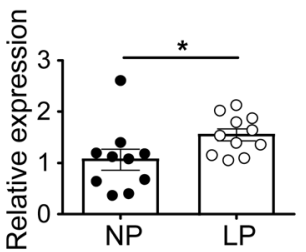

Agtr1b

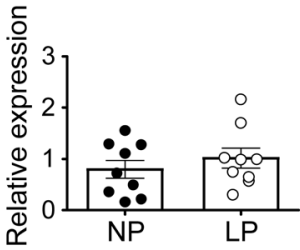

B

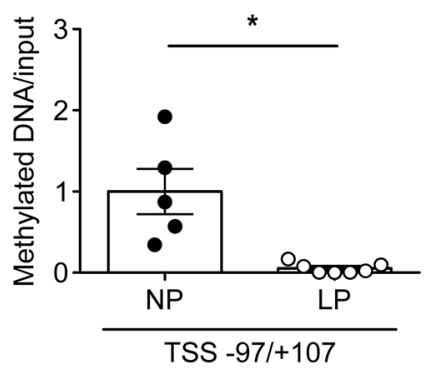

D

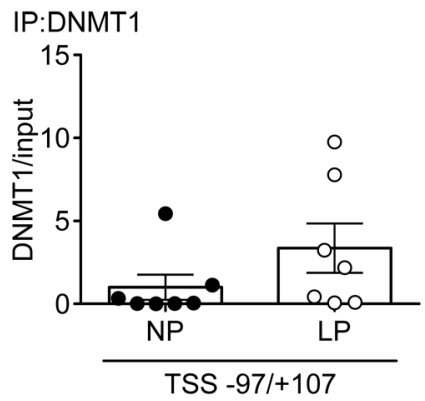

IP:DNMT3a

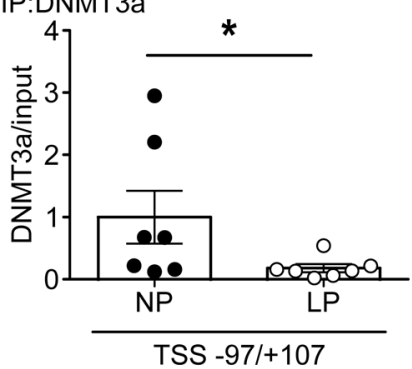

C
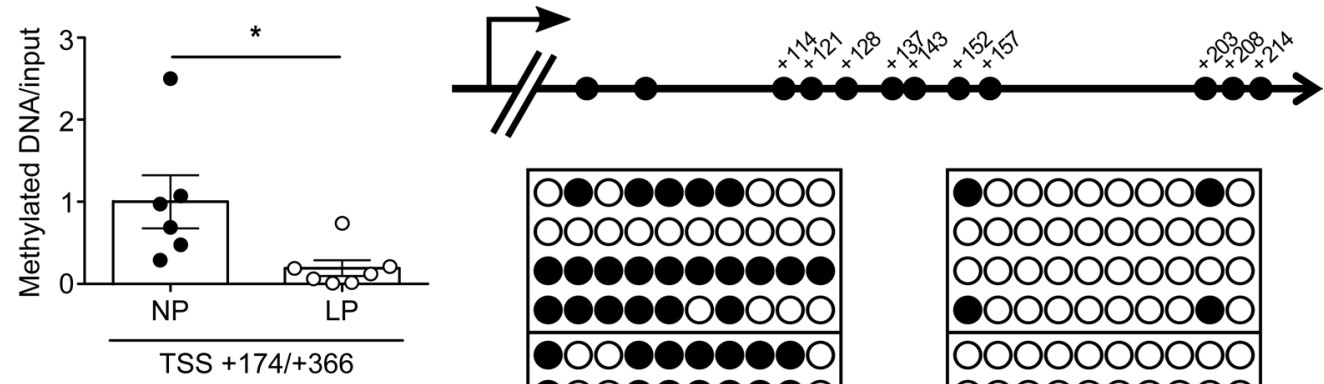

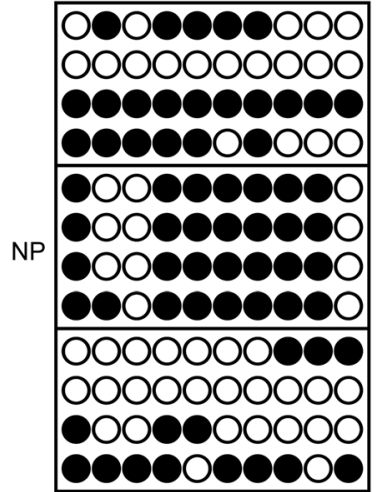

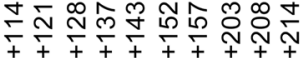

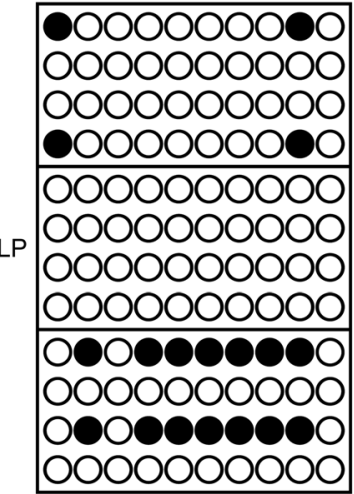

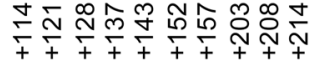

Figure 2. Offspring of pregnant rats treated with a low-protein diet (LP). (A) mRNA levels of Dnmt1 ( $n=8-11)$, Dnmt3a ( $n=11-13)$, Dnmt3b ( $n=12)$, Agtr1a $(n=9)$, and Agtr1b $(n=10)$ in NP-treated or LP-treated offspring. Filled circles, NP group; open circles, LP group. (B) Quantitation of DNA methylation (by MeDIP) at the Agtr7a locus in regions $-97 /+107$ and $+174 /+366$ relative to the transcription start site (TSS) in NP-treated $(n=5$ for $-97 /+107 ; n=6$ for $+174 /+366)$ and LP-treated ( $n=7)$ offspring. (C) Bisulfite sequence analysis of the Agtr1a locus in the PVN from 12-week-old NP-treated or LP-treated offspring. Top, schematic diagram of the Agtr1a locus. Dashes and numbers indicate the positions of the cytosine residues of CpC dinucleotides relative to the TSS (+1). Bottom, DNA methylation status of the CpG sites between +114 and +214 bp relative to the TSS. Filled circles, methylated CpG sites; open circles, demethylated CpG sites. (D) ChIP assays showing DNMT1 (top) and DNMT3a (bottom) binding to the regions $-97 /+107$ ( $n=7$ and 7 for DNMT1; $n=9$ and 11 for DNMT3a) and $+174 /+366$ relative to the TSS ( $n=6$ and 7 for DNMT1; $n=10$ and 8 for DNMT3a, NP and LP, respectively), in the PVN of NP-treated and LP-treated offspring. Filled circles, NP-treated offspring; open circles, LP-treated offspring. Throughout, data represent means $\pm S E M$. ${ }^{*} P<0.05$ versus control offspring ( $t$ test).

treatment (Figure 4E). Moreover, the observation that upregulation of Agtr1a induced by Dnmt3a silencing was not further increased by additional treatment with dexamethasone (Figure 4E) implies that DNMT3a is involved in dexamethasone-induced upregulation of Agtrla expression. Thus, dexamethasone decreases DNA methylation by releasing DNMT3a from the gene, and in turn, DNA demethylation promotes transcription of Agtr1a, suggesting the importance of DNMT3a in dexamethasone-induced DNA demethylation and the subsequent upregulation of Agtrla mRNA in the hypothalamic cells. 
A

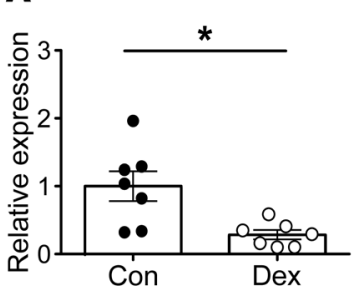

B
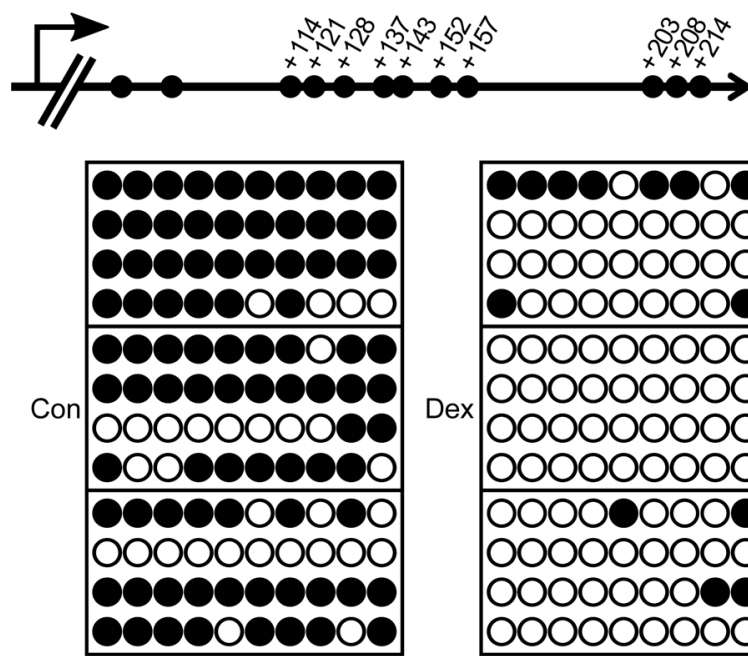

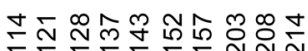

Dnmt3a
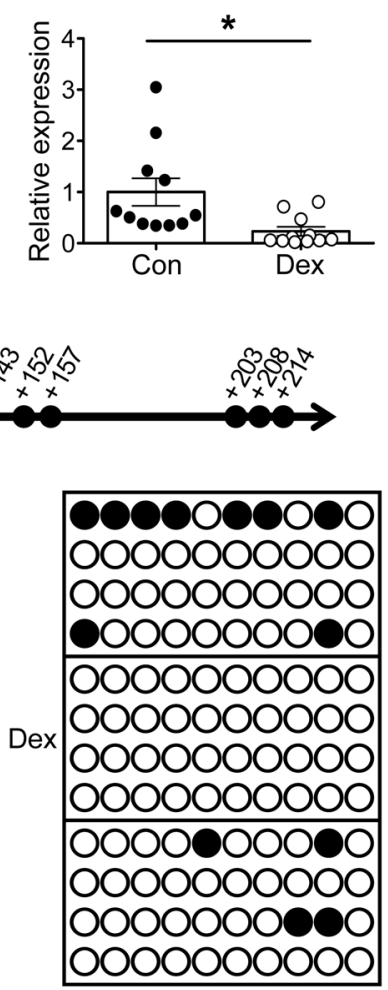

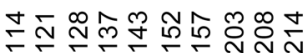
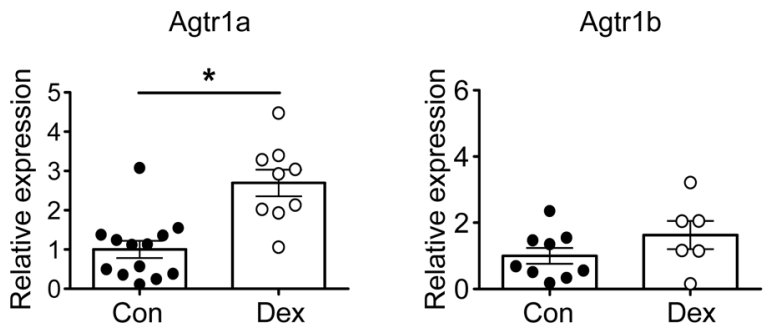

C
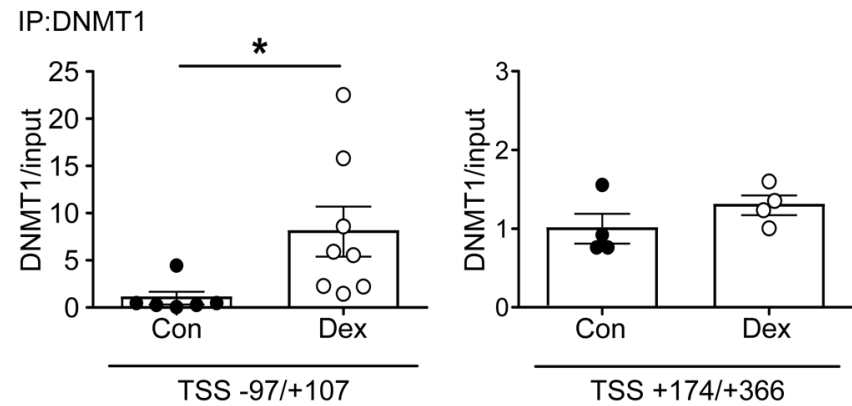

IP:DNMT3a
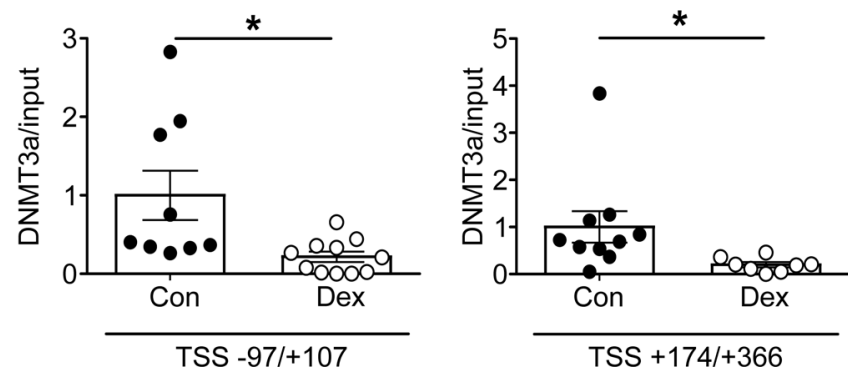

Figure 3. Offspring of pregnant rats treated with dexamethasone (Dex). (A) Levels of Dnmt1 $(n=7)$ and Dnmt3a $(n=11)$ mRNA in control and Dex-treated offspring, and levels of Agtr1a and Agtr1b mRNA in control ( $n=13$ and 9, respectively) and Dex-treated ( $n=9$ and 6, respectively) offspring. (B) Bisulfite sequence analysis of the Agtr1a locus in the PVN from 12-week-old control and Dex-treated offspring. Top, schematic diagram of the Agtr1a locus. Dashes and numbers indicate the positions of the cytosine residues of $\mathrm{CpG}$ dinucleotides relative to the TSS (+1). Bottom, DNA methylation status of the CpG sites between +114 and +214 bp relative to the TSS. Filled circles, methylated CpG sites; open circles, demethylated CpG sites. (C) ChIP assays showing DNMT1 (top) and DNMT3a (bottom) binding to the sites -97 to +107 ( $n=6$ and 8 for DNMT1, and $n=9$ and 11 for DNMT3a, respectively) and +174 to +366 relative to the TSS ( $n=4$ and 4 in DNMT1, and $n=10$ and 8 in DNMT3a, respectively), in the PVN of control and Dex-treated offspring. Filled circles, control; open circles, Dex-treated offspring. Throughout, data represent the means $\pm S E M .{ }^{*} P<0.05$ versus control offspring ( $t$ test).

Salt-sensitive hypertension in offspring of pregnant hypothalamus-specific Dnmt3a-deficient mice. To confirm the involvement of DNMT3a in aberrant DNA methylation of Agtrla and the resultant salt-sensitive hypertension, we administered the HS diet to Sim1-Cre Dnmt3a-KO mice. As previously reported (23), BW at week 12 was higher in the KO mice than in control flox mice (Figure 5A). Dnmt3a-deficient mice showed increased expression of Agtrla mRNA in the PVN (Figure 5B), in the absence of dexamethasone treatment during pregnancy (Supplemental Figure 1), together with an increase in BP (Figure 5C). HS diet further increased BP in Dnmt3a-deficient mice but not in the flox mice (Figure 5C). Thus, chronic deletion of $D n m t 3 a$ from the hypothalamic neuron develops salt-sensitive hypertension by upregulation of Agtrla in the PVN, even without prenatal exposure to excess glucocorticoid.

The PVN is composed of neurons, glia, and astrocytes. To determine where Agtrla is expressed, we performed in situ hybridization of the PVN in Dnmt3a-deficient mice (Figure 5D) and dexamethasone-treated offspring (Supplemental Figure 8). We observed no staining of Agtrla mRNA in cells positive for markers of glia and astrocytes (Figure 5E), confirming that Agtr1a is expressed mainly in neurons, as previously reported (29).

The absence of salt-sensitive hypertension in offspring of pregnant Agtr1a-deficient mice treated with dexamethasone. Expression of Agtr1a mRNA in the PVN was significantly higher in offspring of C57BL6/J WT mice treated with dexamethasone during pregnancy (Figure 6A), and this increase was accompanied by salt-induced BP elevation and reduced expression of Dnmt3a mRNA in the PVN (Figure 6B), consistent 
A

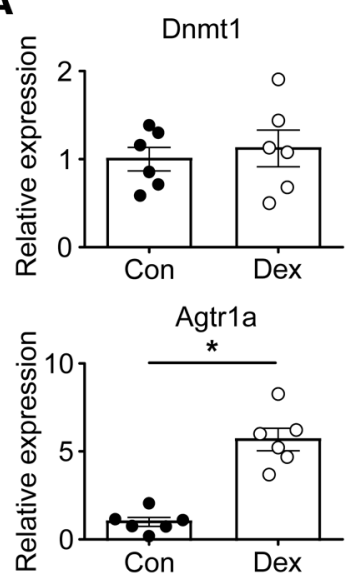

B

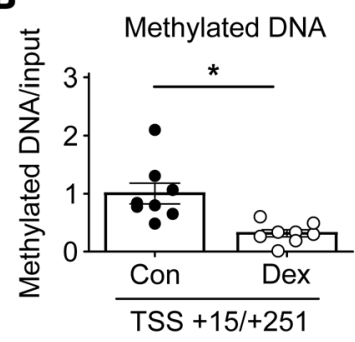

D

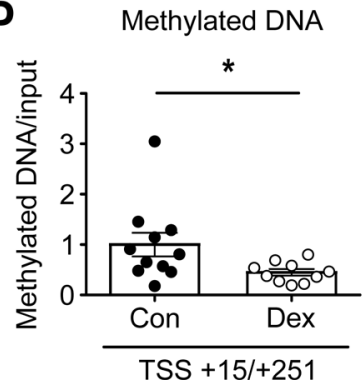

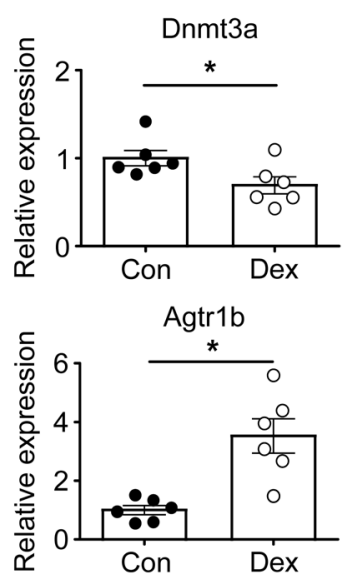

C

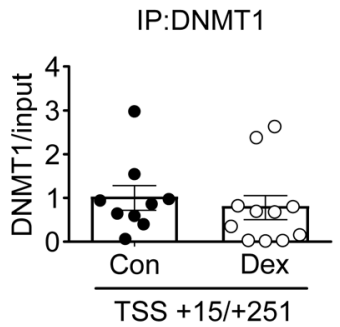

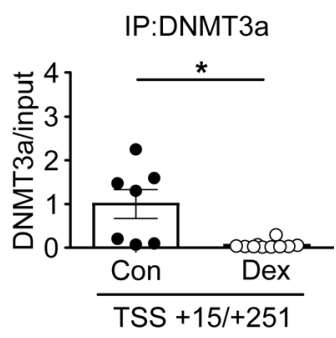

Figure 4. Effect of dexamethasone (Dex) on Agtr1a mRNA and DNA methylation of the Agtr1a promoter in the immortal mouse fetal PVN neuronal cell line, N39. (A) Real-time PCR of Dnmt1, Dnmt3a, Agtr1a, and Agtr1b mRNA following treatment for 6 days with vehicle $(n=6)$ or Dex $(n=6)$. (B) Quantitation of DNA methylation (by MeDIP) at the Agtr1a gene $+15 /+251$ from the transcription start site in vehicle-treated or Dex-treated cells (each $n$ = 8). (C) ChIP assays of DNMT1 (left) and DNMT3a (right) binding to the site $+15 /+251$ relative to the TSS in vehicle-treated or Dex-treated cells ( $n=$ 9 and 10 in DNMT1, and $n=7$ and 10 in DNMT3a, respectively). (D) siRNA against DNMT3a $(n=10)$ significantly decreased DNA methylation of Agtr1a relative to scrambled siRNA $(n=11)$. (E) Effect of Dex treatment on Agtria mRNA expression in cells transfected with siDnmt3a (control and Dex, $n=12$ and 11, respectively) or scrambled RNA (control and Dex, $n=10$ and 8, respectively). (A-C) Filled circles, vehicle-treated cells; open circles, Dex-treated cells. (D-E) Filled circle, cells treated with scrambled RNA; open circles, cells treated with siRNA against Dnmt3a. Data represent means \pm SEM. ${ }^{*} P<0.05$ (A-D) $t$ test; (E) Kruskal-Wallis test with post hoc Dunn's multiple comparison.

\section{E}

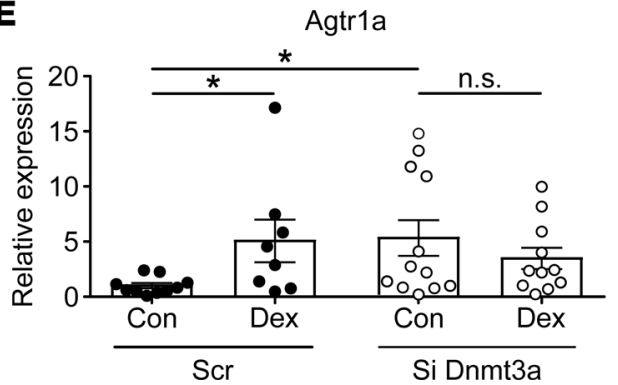

with the results obtained in dexamethasone-treated rat offspring (Figure 3A and Figure 1E, respectively). By contrast, Agtrla deficiency abolished salt-induced elevation of BP in the dexamethasone-exposed offspring (Figure 6B), concomitant with reduced expression of Dnmt3a and Dnmt1 in the PVN (Figure 6C). The sustained downregulation of Dnmt3a mRNA without salt-induced elevation of BP implies that aberrant DNA methylation is persistent, rather than secondary to the BP rise. Given that BP elevation can be induced by optogenetic stimulation of PVN AT1a neurons (17), these findings indicate that epigenetic modulation of Agtrla plays a critical role in salt-sensitive hypertension in offspring exposed prenatally to excessive glucocorticoid (Figure 6D).

\section{Discussion}

We present evidence demonstrating that an epigenetic mechanism underlies hypothalamic angiotensin signaling and leads to the development of salt-sensitive hypertension induced by the prenatal programming resulting from parental exposure to excess glucocorticoid. Specifically, we show that DNA demethylation caused by decreased binding of DNMT3a to the Agtr1a gene induces upregulation of Agtr1a mRNA in the PVN and that the increased angiotensin signaling in the hypothalamus, in turn, leads to salt-induced BP elevation in offspring of pregnant mothers receiving a LP or treated with dexamethasone. Given the importance of central angiotensin signaling in prenatal programmed hypertension (13, 15), Agtr1a deficiency attenuated salt-induced BP elevation induced by prenatal dexamethasone treatment, and dexamethasone treatment - in vitro - increased expression of Agtrla mRNA in cultured PVN cells. Chronic deletion of $D n m t 3 a$ from the hypothalamus induces upregulation of Agtr1a mRNA in the PVN and subsequently results 
A

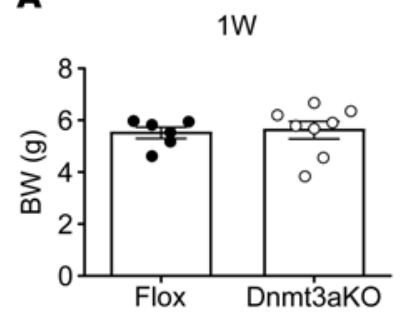

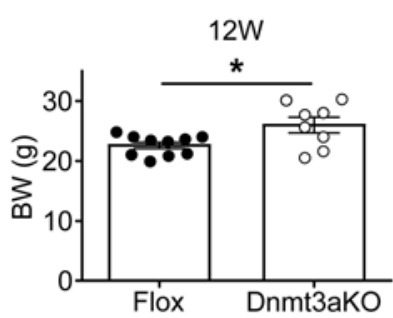

D

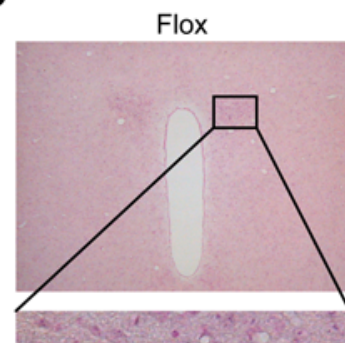

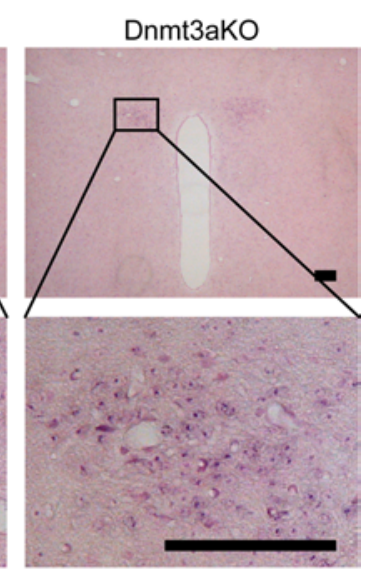

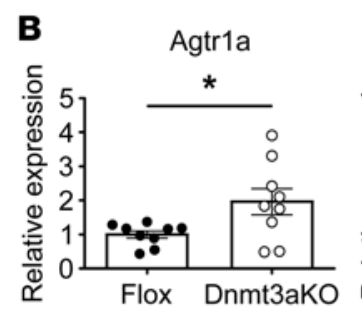

C

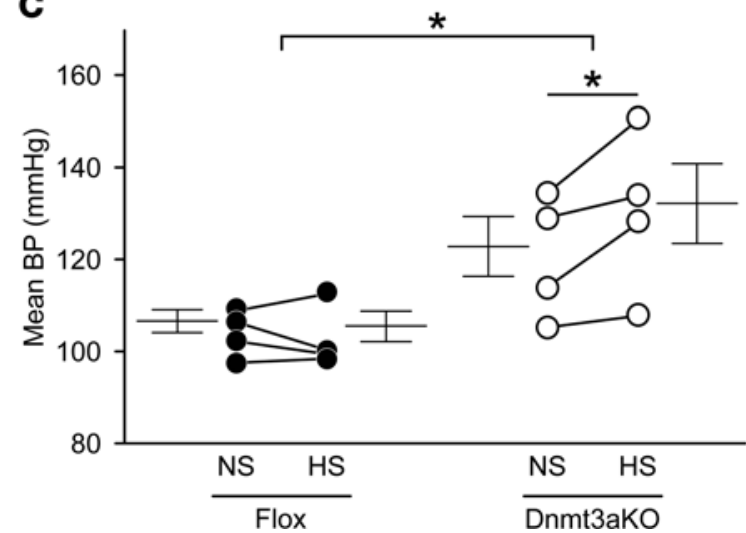

Agtr1b
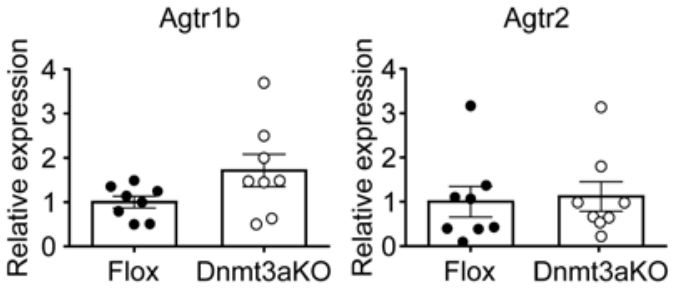

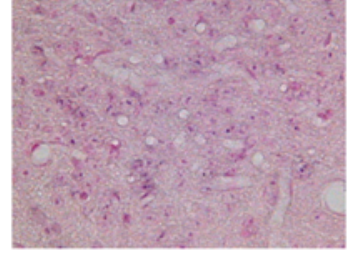

E

Flox
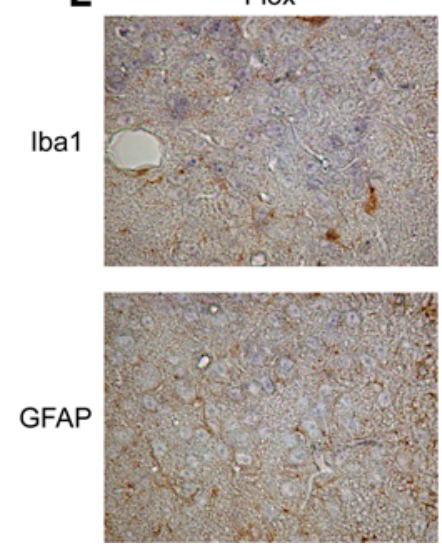
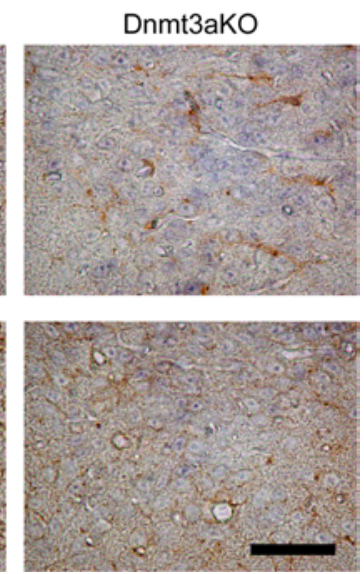

Figure 5. Salt-sensitive hypertension in offspring of hypothalamic neuron-specific Dnmt3a-KO mice without dexamethasone (Dex) treatment during pregnancy. (A) BW at weeks 1 and 12 in the flox mice ( $n=6$ and 10, respectively) and hypothalamic neuron-specific Dnmt3a-KO mice ( $n=8$ and 8 , respectively). Filled circle, Dex-untreated flox mice; open circle, Dex-untreated Dnmt3a-KO mice. (B) Real-time PCR of Agtr1a $(n=9)$, Agtr1b ( $n=8)$, and Agtr2 ( $n=$ 8) mRNA in PVN of flox and Dnmt3a-KO mice. Filled circle, Dex-untreated flox mice; open circle, Dex-untreated Dnmt3a-KO mice. (C) Mean BP by radiotelemetry before and after 1 week of HS in Dex-untreated flox mice $(n=4$, left) and Dex-untreated Dnmt3a-KO mice $(n=4$, right). Filled circle, Dex-untreated flox mice; open circles, Dex-untreated Dnmt3a-KO mice. In A and B, ${ }^{*} P<0.05$ versus Dex-untreated flox mice ( $t$ test); in $\mathbf{C}$, ${ }^{*} P<0.05$ versus HS-treated flox mice or NS-treated Dnmt3a-KO mice (2-way repeated ANOVA, Bonferroni post hoc text). (D) In situ hybridization of Agtr1a mRNA in the PVN of Sim1-Cre Dnmt3a-KO (right) and flox mice (left) (upper panels, low power; lower panels, high power). Hybridization using an antisense probe indicates expression of Agtr1a mRNA (purple, lower panel). Hybridization using the sense probe yielded no detectable signals in the PVN (data not shown). Scale bar: $100 \mu \mathrm{m}$. (E) Upper panels show staining for lba1, a marker of glia cells (brown), and lower panels show GFAP, a marker of astrocytes (brown). Agtr1a (blue) colocalized with neither lba1 nor GFAP, suggesting that it is expressed mainly in neuronal cells. The expression pattern was not affected by Sim1-Cre Dnmt3a-KO. Scale bars: $50 \mu \mathrm{m}$.

in the development of salt-sensitive hypertension in offspring, even without dexamethasone treatment or a LP. Taken together, our results suggest that aberrant DNA methylation by a glucocorticoid-induced decrease in DNMT3a expression and activity, and concurrent upregulation of Agtrla mRNA in the hypothalamus, plays a critical role in the development of prenatal programmed salt-sensitive hypertension.

In agreement with the proposed link between obesity and hypertension, offspring of pregnant mothers receiving a LP or dexamethasone treatment exhibited a low weight at birth but gradually gained weight after birth and became obese at week 12, the time at which they acquired salt-sensitive hypertension. Obesity is associated with salt-sensitive hypertension (30-32). Specifically, high-fat diet-induced upregulation of Agtrla expression in the hypothalamus is mediated by hyperleptinemia (33), and the elevated sensitization of central Ang II results, in turn, in sympathetic overactivity $(12,13,16,33-35)$. However, neither expression of Lep mRNA in adipose tissue at week 1 nor serum leptin concentration at week 12 was elevated in LP-treated offspring, implying that leptin makes little if any contribution to prenatal programmed hypertension. Injection of Agtrla antisense into the PVN decreases salt-sensitive hypertension in transgenic rats overexpressing 
A

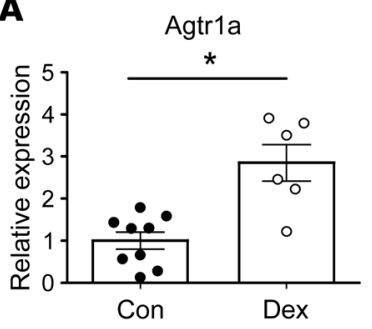

Dnmt1

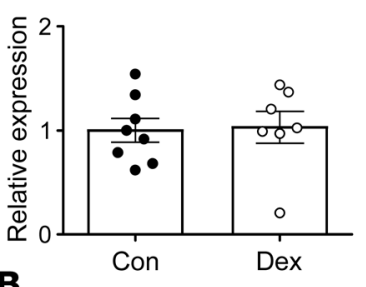

B

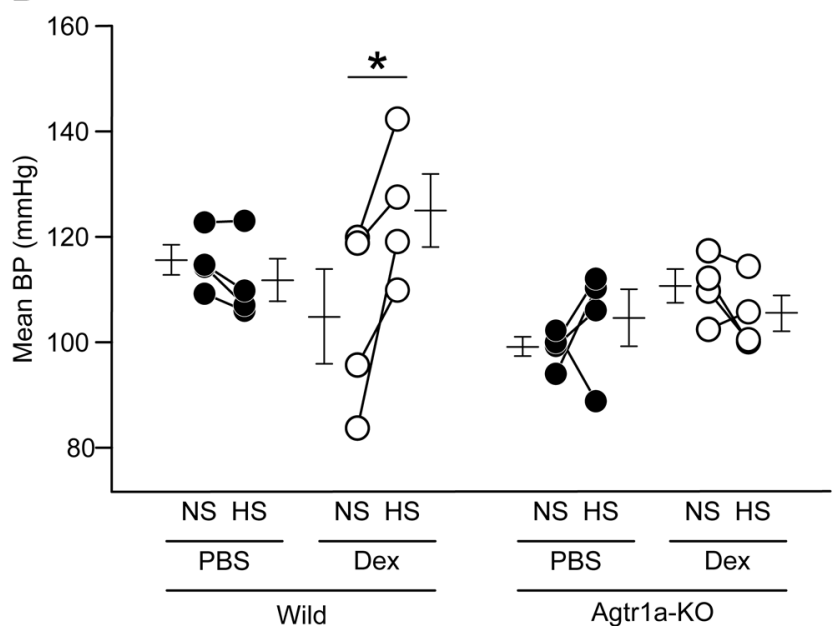

C

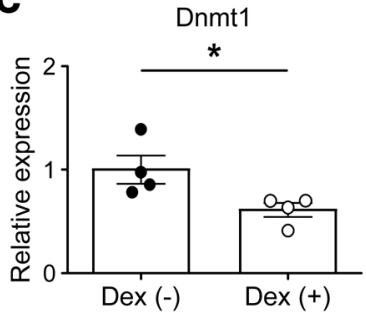

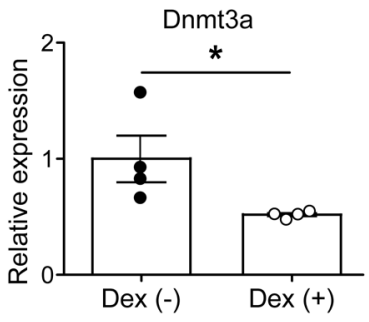

D

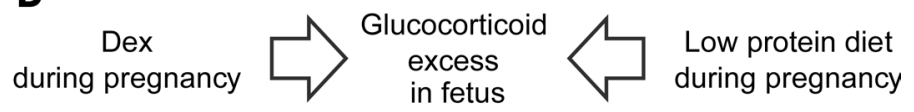

PVN in hypothalamus

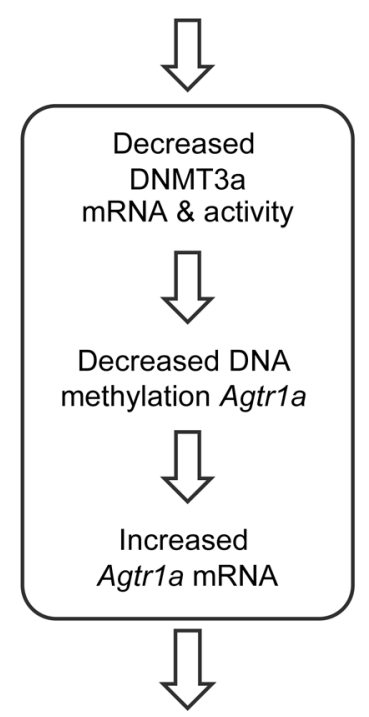

Salt-Sensitive hypertension

Figure 6. Offspring of pregnant C57BL6/J WT mice and pregnant Agtr1a-KO mice treated with dexamethasone (Dex). (A) Real-time PCR of Agtr1a, Agtr1b, Dnmt1, and Dnmt3a mRNA in the paraventricular nucleus (PVN) of offspring of Dex-untreated $(n=6-9)$ and Dex-treated pregnant C57BL6/J mice $(n=4-7)$. Filled circles, Dex-untreated WT mice (Con); open circles, Dex-treated WT mice (Dex). (B) Mean BP by radiotelemetry before and after 1 week of HS treatment in offspring of pregnant WT mice (left) and pregnant Agtr1a-KO mice (right) treated with or without Dex. Filled circles, Dex-untreated WT mice and Agtr1aKO mice; open circles, Dex-treated WT mice and Agtr1a-KO mice (WT, $n=4$; Agtr1a-KO, $n=4)$. (C) Real-time PCR of Dnmt1 and Dnmt3a mRNA in Dex-untreated Agtr1a-KO mice $(n=4)$ and Dex-treated Agtr1a-KO mice $(n=4)$. Filled circles, Dex-untreated Agtr1a-KO mice; open circles, Dex-treated Agtr1a-KO mice. Throughout, data represent means $\pm \mathrm{SEM}$. In A and $\mathbf{C},{ }^{*} P<0.05$ versus Dex-untreated WT mice or Dex-untreated Agtr1a-KO mice ( $t$ test); in $\mathbf{B}$, ${ }^{*} P<$ 0.05 versus NS-treated offspring of pregnant WT mice treated with Dex (2-way repeated ANOVA, Bonferroni post hoc text). (D) Model of prenatal programmed hypertension. A low-protein diet, as well as treatment of Dex, during pregnancy induces exposure to excessive glucocorticoid in the fetus, through the decreased 11ß-HSD2 activity. Excessive glucocorticoid decreases Dnmt3a mRNA and activity, concomitant with DNA demethylation and Agtr1a upregulation in the PVN of hypothalamus of the offspring; the increased angiotensin signaling in the hypothalamus, in turn, develops salt-sensitive hypertension.

RAS components in brain tissue (16), and PVN-specific deletion of Agtrla inhibits obesity-induced hypertension through inhibition of sympathetic overactivity, concomitant with augmentation of diet-induced BW gain (36). Together with these previous findings, our results demonstrate that upregulation of hypothalamic Agtr1a expression not only leads to salt-sensitive hypertension, but also serves as negative feedback signal that activates neurons, thereby alleviating weight gain and obesity in offspring exposed prenatally to excessive glucocorticoid. Several investigators have demonstrated that activation of proinflammatory protein NF- $\mathrm{kB}$ in pro-opiomelanocortin neurons of the hypothalamus underlies obesity-related hypertension $(33,35,37,38)$. Obesity-induced inflammation in the hypothalamus increases Agtrla expression in the PVN and increases BP responsiveness to icv infusion of Ang II. By contrast, icv infusion of the TNF- $\alpha$ synthesis inhibitor decreases Agtrla expression, thereby inhibiting the increase in angiotensin responsiveness (34). Of note, there is accumulating evidence showing that, in contrast to the antiinflammatory action of low physiological doses of glucocorticoids, excessive glucocorticoid has proinflammatory effects in the brain (39). Thus, neonatal programmed hypertension 
induced by exposure to excessive glucocorticoid might be attributable to obesity-induced inflammation in the hypothalamus and the subsequent overactivity of central angiotensin signaling.

Based upon the importance of central angiotensin signaling in salt-sensitive hypertension, the programming of hypothalamic Agtrla gene expression in offspring may lead to salt-sensitive hypertension possibly through sympathetic overactivity. Wang et al. showed upregulation of Agtr1a mRNA in the hypothalamic nuclei of salt-sensitive hypertensive rats compared with salt-resistant normotensive rats and also reported that icv administration of captopril caused a clear decrease in BP (27). Moreover, either injection of Agtrla antisense to the PVN or renal denervation attenuates salt-induced elevation of BP in a rat model of salt-sensitive hypertension with an abnormal hypothalamic-renal sympathetic nervous system $(8-10,16)$, suggesting that central angiotensin signaling plays a key role in increased sympathetic activity during the development of salt-sensitive hypertension (40). Regarding the mechanism of AT1a activation-induced sympathetic overactivity, Stern et al. demonstrated that ATla in the astrocytes of the PVN plays a key role in the activation of the sympathetic nervous system (41). Specifically, they showed that hypothalamic AT1a activation excites PVN neurons indirectly via astrocyte ATla activation-induced inhibition of glutamate reuptake in astrocytes, leading to enhanced glutamate receptor excitation of presympathetic PVN neurons, and results in elevated downstream activity in sympathetic fibers and BP. Thus, it is possible that AT1a activation in astrocytes plays a critical role in the excitation of PVN neurons in prenatal programmed hypertension. However, in situ hybridization revealed no staining of Agtrla mRNA in cells positive for markers of glia and astrocytes, as previously reported (27), and the Agtr1a expression pattern was not affected by Sim1-Cre Dnmt3a-KO or dexamethasone treatment, suggesting that Agtrla is expressed mainly in neurons. Moreover, chronic deletion of DNMT3a from hypothalamic neurons increased mRNA expression of PVN Agtrla, and the mice developed salt-sensitive hypertension even without receiving a LP or dexamethasone treatment during pregnancy. These results suggest that DNA demethylation of Agtr1a by DNMT3a downregulation in hypothalamic neurons plays a critical role in the upregulation of PVN Agtrla expression by prenatal glucocorticoid excess, leading to prenatal programmed salt-sensitive hypertension, possibly via sympathetic overactivity.

The epigenome, which includes the covalent modifications of DNA and its transcriptional machinery, is the key determinant of gene expression, second in importance only to transcription factor binding (21), leading to persistent phenotypic changes in individual organs $(41,42)$. Neonatal glucocorticoid exposure makes the initial contribution to the elevated expression of Agtrla, and epigenetic modulation might contribute to the persistent Agtrla upregulation in the hypothalamus of offspring (15). Certainly, transient exposure of PVN cells to dexamethasone in vitro causes epigenetic changes by DNMT3a and altered expression of Agtr1a, and both epigenetic and gene expression changes persist despite a background of normal glucocorticoid exposure during adulthood. Indeed, a maternal LP leads to hypomethylation of the $\mathrm{CpG}$ islands in the promoters of RAS genes, and upregulation of these genes in the whole brain, in offspring $(24,43)$. Of note, the whole brain, and even the hypothalamus, is composed of various nuclei that have individual functions. Among the hypothalamic nuclei, the PVN has emerged as one of the most important autonomic control centers in the brain and contains neurons that play essential roles in energy balance and circulatory regulation. We observed aberrant DNA methylation and concurrent upregulation of Agtrla mRNA expression in the PVN of dexamethasone-treated offspring. Upregulation of Agtr1a mRNA occurred concomitantly with the reduction in the mRNA expression of Dnmt3a associated with reduced activity and binding of DNMT3a, but not DNMT1, to the Agtrla locus. Thus, Agtrla is a target gene of DNMT3a, but not rather than DNMT1. Given the close link between DNMT3a and Agtr1a mRNA expression in prenatal programmed hypertension, the mechanism underlying Dnmt3a transcription during salt-induced BP elevation needs to be clarified. In contrast with PVN Agtrla mRNA, which is expressed mainly in neural cells, the ubiquitous expression of Dnmt3a in the PVN, which consists of multiple cell types including both neurons and glia, makes it difficult to assess the full extent of DNMT3a alterations. Nevertheless, chronic deletion of Dnmt3a from hypothalamic neurons could induce DNA demethylation and concurrently increased expressions of Agtrla mRNA in the PVN, leading to salt-sensitive hypertension. Together, these findings strongly suggest that hypothalamic neuron-specific regulation of DNMT3a activity, and the subsequent DNA methylation changes of Agtr1a, represent a potential mechanism underlying prenatal programmed salt-sensitive hypertension. From the standpoint of mechanism, however, further study is needed to determine whether sensitization of BP responses to a HS diet after LP pregnancy can actually be blocked by replacement of DNMT3a and blockade of Agtr1a within the PVN or, alternatively, by an antagonist-mediated reduction in glucocorticoid signaling. 
In conclusion, the RAS in the CNS, which has emerged as a key contributor to the regulation of $\mathrm{BP}$ (44), plays an important role in prenatal programmed hypertension. Aberrant DNA methylation resulting from glucocorticoid excess during pregnancy underlies persistent alterations of Agtrla mRNA expression in the hypothalamus, likely leading to elevated BP salt-sensitivity. A greater understanding of epigenetic modulations, including DNA methylation of the RAS component genes, may shed light on how the system could be targeted to prevent and treat prenatal programmed hypertension.

\section{Methods}

Animals and experimental design. For the dexamethasone exposure model, pregnant female Sprague-Dawley (SD) rats, C57BL6/J mice, or Agtr1a-KO mice were administered dexamethasone $(200 \mu \mathrm{g} / \mathrm{kg} / \mathrm{d}$ for rats and $100 \mu \mathrm{g} / \mathrm{kg} / \mathrm{d}$ for mice) i.p. from F15-21. For the LP model, pregnant female rats were fed a diet containing $9 \%$ protein from conception until birth. After delivery, the food was reverted to normal chow (23\% protein) and provided ad libitum. Conventional Agtrla-KO mice were purchased from RIKEN (B6; B6CB-Agtr1a<tm1Afu> [RBRC no. RBRC04696]). Sim1-Cre/Dnmt3a-KO mice, which harbor hypothalamic neuron-specific Dnmt3a deletion, were obtained from Daisuke Kohno (Gunma University). All mice were backcrossed on the C57BL6/J background for 6 or more generations. To generate the Sim1-Cre-specific Dnmt3a deletion mice, female mice homozygous for floxed Dnmt3a allele1 (45) were crossed with male mice homozygous for the Sim-Cre transgene (46). For HS loading, food containing $8 \% \mathrm{NaCl}$ was administered for 1 week. Mice and rats were kept at room temperature $\left(22^{\circ} \mathrm{C}-24^{\circ} \mathrm{C}\right)$ with a 12 -hour/12-hour light/ dark cycle, and given access to water ad libitum. We randomly chose the animals for BP measurement, and all the other offspring were used for gene analysis.

$B P$ measurement. Systolic BP and mean arterial pressures (MAP) of conscious rats and mice were monitored using a radiotelemetry system. The animals were anesthetized with pentobarbital sodium, and the tip of the catheter was inserted in the carotid artery of the mouse (PA-C10, Data Sciences International [DSI]) or the abdominal aorta of the rat (PA-C40, DSI), with the telemetry body positioned in a s.c. pocket on the right flank. Baseline measurements were recorded for 2 consecutive days (days 0-2) in rats or mice fed an NS diet. At day 5, posttreatment measurements were recorded for the final 3 consecutive days of the HS diet (days 5-7).

Microarray assay and gene ontology analysis. We extracted RNA from the PVN of control and dexamethasone-treated offspring at 12 weeks of age (each $n=3$ ). An Agilent Gene Chip Whole Rat Genome Microarray Ver3.0 was hybridized for each sample. The raw signal intensities and flags for each probe were calculated from the hybridization intensities and spot information according to procedures recommended by Agilent Technologies using the Flag criteria in the GeneSpring Software. In addition, the raw signal intensities of all samples were normalized using the quantile algorithm in Bioconductor. We selected 912 genes that were upregulated by $\geq 2$-fold relative to the control group and subjected them to pathway analysis using the DAVID 6.8 bioinformatics resource. The data files have been uploaded to the National Center for Biotechnology Information Gene Expression Omnibus (GSE119235; to review GSE119235, please go to https://www.ncbi.nlm.nih.gov/geo/query/acc.cgi?acc=GSE119235 and enter token gbgjiegktxslbel into the box).

DNMT3a activity assay. To evaluate DNMT3a activity in the rat PVN, we lysed cells in hypotonic buffer (10 mM HEPES, $1.5 \mathrm{mM} \mathrm{MgCl}_{2}, 10 \mathrm{mM} \mathrm{KCl}$ ) and homogenized by repeatedly passed through a 26-gauge needle syringe. After centrifuge, we extracted nuclear protein with elution buffer (20 mM HEPES, $1.5 \mathrm{mM}$ $\mathrm{MgCl}_{2}, 0.42 \mathrm{M} \mathrm{NaCl}, 0.2 \mathrm{mM}$ EDTA, 25\% [v/v] glycerol). Nuclear protein was immunoprecipitated overnight at $4^{\circ} \mathrm{C}$ with anti-DNMT3a antibody (ab2850, Abcam). After the pulldown, DNMT3a activity was measured using the DNMT Universal Chemiluminescent Assay Kit (BPS Bioscience).

Cell culture. The immortalized embryonic mouse hypothalamic neuron cell line N39 was purchased from Cosmo Bio. Cells were maintained in high-glucose DMEM (Invitrogen) containing 10\% FBS (Nichirei Bioscience) supplemented with antibiotics $(100 \mathrm{U} / \mathrm{ml}$ penicillin and $100 \mu \mathrm{g} / \mathrm{ml}$ streptomycin; Wako). Mycoplasma contamination was confirmed by using PCR (EZ-PCR mycoplasma Test kit, Cosmo Bio). N39 cells were seeded at $1 \times 10^{6}$ cells per well in $10-\mathrm{cm}$ dishes and maintained in a $37^{\circ} \mathrm{C}$ humidified 5\% $\mathrm{CO}_{2}$ incubator. The next day, 10-100 $\mathrm{nM}$ dexamethasone (Wako) was applied, and the cells were incubated for an additional 1-6 days.

Transfection of siRNA. We transfected $1 \mathrm{nM}$ siRNA into N93 cells using Lipofectamine RNAiMAX (Thermo Fisher Scientific). The sequence of DNMT3a siRNA was UUUCAGUGCACCACAGGAUGUCCUC. 
Scrambled RNA was purchased from Invitrogen. For measurement of gene expression, $1 \times 10^{6}$ cells were collected, whereas for MeDIP, $2 \times 10^{7}$ cells were collected. Total RNA or DNA was extracted 6 days after transfection. To determine the efficacy of knockdown, total RNA was extracted as noted above, and the level of the target mRNA was measured (Supplemental Figure 7).

ChIP assay. Brain tissues of the PVN were placed in $0.5 \mathrm{ml}$ of PBS and homogenized by 20 passages through a 25-gauge needle on a syringe. After cell separation, ChIP was performed using the ChIP-IT Express kit (Active Motif). In brief, cells were fixed with 1\% formaldehyde for 10 minutes at room temperature; then, crosslinking was stopped by the addition of $125 \mathrm{mM}$ glycine. The cells were lysed with lysis buffer, and chromatin was sheared using a sonicator (Bioruptor UCD-250, CosmoBio) for 10 pulses of 30 seconds each. The efficacy of shearing was confirmed by agarose gel electrophoresis (200-1,000 bp). ChIP was carried out by mixing $20 \mu \mathrm{g}$ of chromatin, protein G magnetic beads, $2 \mu \mathrm{g}$ of the indicated antibody (mouse monoclonal anti-DNMT1, 39204, Active Motif; rabbit polyclonal anti-DNMT3a antibody, ab2850, Abcam), and ChIP buffer 1 and incubating overnight at $4^{\circ} \mathrm{C}$. Subsequently, the beads were washed 3 times with buffers included in the kit, and crosslinks were reversed by incubation with elution buffer AM2 for 15 minutes at $95^{\circ} \mathrm{C}$. The eluted DNA was subjected to qPCR using primers hybridizing to the indicated regions near the TSS of Agtrla (Supplemental Table 2). For input DNA, Agtrla DNA was used except in experiments comparing rats on a LP versus a NP (Figure 2D), in which Agtrla PCR was not unsuccessful for unknown reasons. Actb DNA was used instead. The Actb primers were: F, 5'-TCCAATCCAGACCCCGTGTG-3'; R, 5'-GCCTGTATTCTGGGGGTCAC-3'.

MeDIP. MeDIP was performed using Methyl Collect Ultra Tissue Methylated DNA Immunoprecipitation Kit (Active Motif). Genomic DNA was extracted from a mouse embryonic hypothalamic cell line (N39), enzymatically digested into fragments ranging in size from 200-1,000 bp and divided into IP and input portions. IP DNA was incubated with His-tagged-MBD2b/MBD3L1 protein complex in the kit to bind methylated DNA; normal mouse IgG was used as a negative control (sc-2025, Santa Cruz Biotechnology). Methylated DNA was subjected to qPCR using the primers described above. Relative enrichment of target sequences after MeDIP was expressed as ratios of the signals in IP DNA versus input DNA. Details of the primers used are provided in Supplemental Table 2.

Bisulfite sequencing. Sodium bisulfite treatment of genomic DNA was performed with the CpGenome Turbo Bisulfite Modification Kit (MilliporeSigma). Sequential PCR amplification of the genes of interest was performed using specific primers. The amplicons were ligated into vector pMD20T (Takara Bio) and sequenced. Six or 7 bacterial colonies were picked per amplicon. A web-based quantification tool for methylation analysis was used for bisulfite sequencing analysis of CpG methylation (http://quma.cdb.riken.jp/)

$q P C R$ analysis. Total RNA was extracted from cells and PVN (QIAGEN) or ISOGEN lysis buffer (Wako). For qPCR, TaqMan Gene Expression Assays were utilized with a 7300 RT-PCR system (Thermo Fisher Scientific). Denaturation was carried out at $95^{\circ} \mathrm{C}$ for 15 seconds, and annealing and extension were performed at $60^{\circ} \mathrm{C}$ for 1 minute for 40 cycles. To compare gene expression levels, the comparative Ct method was used. Actb (encoding $\beta$-actin) was used as an endogenous control.

In situ hybridization of Agtrla. To evaluate Agtrla expression in the PVN, tissue was fixed with paraformaldehyde/phosphate buffer at $4^{\circ} \mathrm{C}$ for 24 hours. Paraffin-embedded sections were cut to a thickness of $4 \mu \mathrm{m}$. A $180 \mathrm{bp}$ DNA fragment corresponding to nucleotide positions 1,651-1,830 of mouse Agtr1a (GeneBank accession number NM_177322.3) was subcloned into vector pGEMT-Easy (Promega) and used for generation of sense or antisense RNA probes. RNA probes were synthesized using the DIG RNA labeling kit (Roche Diagnostics). Mouse tissues were fixed with G-Fix (GenoStaff) and sectioned at a thickness of $8 \mu \mathrm{m}$. In situ hybridization was performed with the ISH Reagent Kit (GenoStaff). Tissue sections were fixed with G-Nox and rehydrated through an ethanol series and PBS. The sections were fixed with $10 \%$ Formalin in PBS for 30 minutes at $37^{\circ} \mathrm{C}$, washed in distilled water, and placed in a Coplin jar containing $1 \times$ G-Wash (GenoStaff), equivalent to $1 \times$ SSC. Hybridization was performed for 16 hours at $60^{\circ} \mathrm{C}$ with the indicated probes at a concentration of $250 \mathrm{ng} / \mathrm{ml}$ in G-Hybo (GenoStaff). After hybridization, the sections were washed in $1 \times \mathrm{G}$-Wash for 10 minutes at $60^{\circ} \mathrm{C}$. Brain sections were visualized by NBP/BCIP (MilliporeSigma). The sections were counterstained with Kernechtrot (Muto Pure Chemicals).

To determine whether Agtrla is expressed in glia or astrocytes, we stained cells with anti-Iba1 (019-19741, Wako) or anti-GFAP rabbit polyclonal antibody (Z0334, DAKO) overnight at $4^{\circ} \mathrm{C}$. After 2 washes with TBS Tween 20 and 1 wash with TBS, the secondary antibody (anti-rabbit Ig Biotin 
[E0432, DAKO]) was applied for 30 minutes at room temperature. The samples were washed with TBS and developed with HRP-streptavidin (426062, Nichirei).

Serum leptin concentration. Serum leptin was measured by a commercial laboratory (SRL Inc.) using the multispecies Leptin-RIA kit (MilliporeSigma). Before sampling of blood, rats were starved for at least 6 hours.

Statistics. Some PCR data were omitted when the values were 3 SD outside of the mean or RNA/DNA purity was poor. All data are presented as means \pm SEM. For gene expression analysis, statistical differences were determined by 2-tailed $t$ test or by 1-way ANOVA with a post hoc test (Dunnett or Student-Newman-Keuls) unless otherwise noted. Differences with $P$ values less than 0.05 were considered statistically significant. BP differences were analyzed by 2-way repeated ANOVA.

Study approval. Animal experiments protocols were approved by the Experimental Animal Research Committee at the University of Tokyo (no. P15008).

\section{Author contributions}

$\mathrm{KMF}, \mathrm{TF}$, and $\mathrm{MN}$ conceived and designed the project. $\mathrm{KMF}$ and $\mathrm{MN}$ performed the experiments. KMF and $\mathrm{MN}$ analyzed the data. WK, NA, KU, DH, RL, DK, SO, TM, and TS helped with experimental procedures, analyzed data, and discussed the results. DK provided Dnmt3a-KO mice. TF, KMF, MN, and TM wrote the manuscript.

\section{Acknowledgments}

This work was supported by JSPS KAKENHI (grant no. 24790834), AMED-CREST, JP17ek0210093, and JP18ek0210093 from Japan Agency for Medical Research and Development (AMED).

Address correspondence to: Toshiro Fujita, Division of Clinical Epigenetics, Research Center for Advanced Science and Technology, The University of Tokyo, 4-6-1 Komaba, Meguroku, Tokyo $153-$ 8904, Japan. Phone: 81.3.5452.5070; Email: Toshiro.FUJITA@rcast.u-tokyo.ac.jp. Or to: Mitsuhiro Nishimoto, Division of Clinical Epigenetics, Research Center for Advanced Science and Technology, The University of Tokyo, 4-6-1 Komaba, Meguroku, Tokyo 153-8904, Japan. Phone: 81.3.5452.5070; Email: nishimoto-tky@umin.ac.jp.

1. Barker DJ, Osmond C, Golding J, Kuh D, Wadsworth ME. Growth in utero, blood pressure in childhood and adult life, and mortality from cardiovascular disease. BMJ. 1989;298(6673):564-567.

2. Hanson MA, Gluckman PD. Early developmental conditioning of later health and disease: physiology or pathophysiology? Physiol Rev. 2014;94(4):1027-1076.

3. Seckl JR. Glucocorticoids, feto-placental $11 \beta$-hydroxysteroid dehydrogenase type 2, and the early life origins of adult disease. Steroids. 1997;62(1):89-94.

4. Vehaskari VM, Woods LL. Prenatal programming of hypertension: lessons from experimental models. J Am Soc Nephrol. 2005;16(9):2545-2556.

5. Manning J, Vehaskari VM. Postnatal modulation of prenatally programmed hypertension by dietary Na and ACE inhibition. Am J Physiol Regul Integr Comp Physiol. 2005;288(1):R80-R84.

6. Tang JI, Kenyon CJ, Seckl JR, Nyirenda MJ. Prenatal overexposure to glucocorticoids programs renal 11 $\beta$-hydroxysteroid dehydrogenase type 2 expression and salt-sensitive hypertension in the rat. J Hypertens. 2011;29(2):282-289.

7. Kinsman BJ, Simmonds SS, Browning KN, Stocker SD. Organum vasculosum of the lamina terminalis detects $\mathrm{NaCl}$ to elevate sympathetic nerve activity and blood pressure. Hypertension. 2017;69(1):163-170.

8. Fujita T, Sato Y. Hypotensive effect of taurine. Possible involvement of the sympathetic nervous system and endogenous opiates. J Clin Invest. 1988;82(3):993-997.

9. Fujita M, Ando K, Nagae A, Fujita T. Sympathoexcitation by oxidative stress in the brain mediates arterial pressure elevation in salt-sensitive hypertension. Hypertension. 2007;50(2):360-367.

10. $\mathrm{Mu} \mathrm{S}$, et al. Epigenetic modulation of the renal $\beta$-adrenergic-WNK4 pathway in salt-sensitive hypertension. Nat Med. 2011;17(5):573-580

11. Baum M. Role of renal sympathetic nerve activity in prenatal programming of hypertension. Pediatr Nephrol. 2018;33(3):409-419.

12. Mizuno M, Lozano G, Siddique K, Baum M, Smith SA. Enalapril attenuates the exaggerated sympathetic response to physical stress in prenatally programmed hypertensive rats. Hypertension. 2014;63(2):324-329.

13. Mizuno M, Siddique K, Baum M, Smith SA. Prenatal programming of hypertension induces sympathetic overactivity in response to physical stress. Hypertension. 2013;61(1):180-186

14. Dagan A, Kwon HM, Dwarakanath V, Baum M. Effect of renal denervation on prenatal programming of hypertension and renal tubular transporter abundance. Am J Physiol Renal Physiol. 2008;295(1):F29-F34.

15. Pladys $\mathrm{P}$, et al. Role of brain and peripheral angiotensin II in hypertension and altered arterial baroreflex programmed during fetal life in rat. Pediatr Res. 2004;55(6):1042-1049.

16. Li P, Morris M, Diz DI, Ferrario CM, Ganten D, Callahan MF. Role of paraventricular angiotensin AT1 receptors in salt-sensitive 
hypertension in mRen-2 transgenic rats. Am J Physiol. 1996;270(5 Pt 2):R1178-R1181.

17. de Kloet $\mathrm{AD}$, et al. A unique "angiotensin-sensitive" neuronal population coordinates neuroendocrine, cardiovascular, and behavioral responses to stress. J Neurosci. 2017;37(13):3478-3490.

18. de Kloet AD, et al. Angiotensin type 1a receptors in the paraventricular nucleus of the hypothalamus protect against diet-induced obesity. J Neurosci. 2013;33(11):4825-4833.

19. Wang L, Hiller H, Smith JA, de Kloet AD, Krause EG. Angiotensin type 1a receptors in the paraventricular nucleus of the hypothalamus control cardiovascular reactivity and anxiety-like behavior in male mice. Physiol Genomics. 2016;48(9):667-676.

20. Aguilera G, Kiss A, Luo X. Increased expression of type 1 angiotensin II receptors in the hypothalamic paraventricular nucleus following stress and glucocorticoid administration. J Neuroendocrinol. 1995;7(10):775-783.

21. Jones PA. Functions of DNA methylation: islands, start sites, gene bodies and beyond. Nat Rev Genet. 2012;13(7):484-492

22. Khurana I, et al. DNA methylation regulates hypothalamic gene expression linking parental diet during pregnancy to the offspring's risk of obesity in Psammomys obesus. Int J Obes (Lond). 2016;40(7):1079-1088.

23. Kohno D, et al. Dnmt3a in Sim1 neurons is necessary for normal energy homeostasis. J Neurosci. 2014;34(46):15288-15296.

24. Goyal R, Goyal D, Leitzke A, Gheorghe CP, Longo LD. Brain renin-angiotensin system: fetal epigenetic programming by maternal protein restriction during pregnancy. Reprod Sci. 2010;17(3):227-238.

25. Weber M, et al. Chromosome-wide and promoter-specific analyses identify sites of differential DNA methylation in normal and transformed human cells. Nat Genet. 2005;37(8):853-862.

26. Roadmap Epigenomics Consortium, et al. Integrative analysis of 111 reference human epigenomes. Nature. 2015;518(7539):317-330.

27. Wang JM, Veerasingham SJ, Tan J, Leenen FH. Effects of high salt intake on brain AT1 receptor densities in Dahl rats. Am J Physiol Heart Circ Physiol. 2003;285(5):H1949-H1955.

28. Fujiki K, Kano F, Shiota K, Murata M. Expression of the peroxisome proliferator activated receptor gamma gene is repressed by DNA methylation in visceral adipose tissue of mouse models of diabetes. BMC Biol. 2009;7:38.

29. de Kloet AD, Liu M, Rodríguez V, Krause EG, Sumners C. Role of neurons and glia in the CNS actions of the renin-angiotensin system in cardiovascular control. Am J Physiol Regul Integr Comp Physiol. 2015;309(5):R444-R458.

30. Chen J, et al. Metabolic syndrome and salt sensitivity of blood pressure in non-diabetic people in China: a dietary intervention study. Lancet. 2009;373(9666):829-835

31. Nagae A, Fujita M, Kawarazaki H, Matsui H, Ando K, Fujita T. Sympathoexcitation by oxidative stress in the brain mediates arterial pressure elevation in obesity-induced hypertension. Circulation. 2009;119(7):978-986.

32. do Carmo JM, da Silva AA, Cai Z, Lin S, Dubinion JH, Hall JE. Control of blood pressure, appetite, and glucose by leptin in mice lacking leptin receptors in proopiomelanocortin neurons. Hypertension. 2011;57(5):918-926.

33. Xue B, et al. Leptin mediates high-fat diet sensitization of angiotensin II-elicited hypertension by upregulating the brain renin-angiotensin system and inflammation. Hypertension. 2016;67(5):970-976.

34. Xue B, et al. Central renin-angiotensin system activation and inflammation induced by high-fat diet sensitize angiotensin II-elicited hypertension. Hypertension. 2016;67(1):163-170.

35. Claflin KE, et al. Angiotensin AT1A receptors on leptin receptor-expressing cells control resting metabolism. J Clin Invest. 2017;127(4):1414-1424.

36. de Kloet $\mathrm{AD}$, et al. Obesity induces neuroinflammation mediated by altered expression of the renin-angiotensin system in mouse forebrain nuclei. Physiol Behav. 2014;136:31-38.

37. Purkayastha S, Zhang G, Cai D. Uncoupling the mechanisms of obesity and hypertension by targeting hypothalamic IKK- $\beta$ and NF-кB. Nat Med. 2011;17(7):883-887.

38. Hall JE, do Carmo JM, da Silva AA, Wang Z, Hall ME. Obesity-induced hypertension: interaction of neurohumoral and renal mechanisms. Circ Res. 2015;116(6):991-1006.

39. Munhoz CD, Sorrells SF, Caso JR, Scavone C, Sapolsky RM. Glucocorticoids exacerbate lipopolysaccharide-induced signaling in the frontal cortex and hippocampus in a dose-dependent manner. J Neurosci. 2010;30(41):13690-13698.

40. Gabor A, Leenen FH. Cardiovascular effects of angiotensin II and glutamate in the PVN of Dahl salt-sensitive rats. Brain Res. 2012;1447:28-37.

41. Stern JE, Son S, Biancardi VC, Zheng H, Sharma N, Patel KP. Astrocytes Contribute to Angiotensin II Stimulation of Hypothalamic Neuronal Activity and Sympathetic Outflow. Hypertension. 2016;68(6):1483-1493.

42. El-Osta A, et al. Transient high glucose causes persistent epigenetic changes and altered gene expression during subsequent normoglycemia. J Exp Med. 2008;205(10):2409-2417.

43. Khurana I, et al. DNA methylation regulates hypothalamic gene expression linking parental diet during pregnancy to the offspring's risk of obesity in Psammomys obesus. Int J Obes (Lond). 2016;40(7):1079-1088.

44. Nakagawa P, Sigmund CD. How Is the Brain Renin-Angiotensin System Regulated? Hypertension. 2017;70(1):10-18.

45. Kaneda M, et al. Essential role for de novo DNA methyltransferase Dnmt3a in paternal and maternal imprinting. Nature. 2004;429(6994):900-903.

46. Balthasar N, et al. Divergence of melanocortin pathways in the control of food intake and energy expenditure. Cell. 2005;123(3):493-505. 